\title{
HELEN FALCON: 'COPDEND'S INTENTION WAS TO TRY AND IMPROVE THE QUALITY OF CPD'
}

\author{
Helen Falcon has just recently retired as Postgraduate Dean for Dental Education and Training for both the \\ Thames Valley and Wessex local offices of Health Education England, and as Chair of the UK Committee of \\ Postgraduate Dental Deans and Directors (COPDEND). Ruth Doherty, BDJ Managing Editor, caught up with \\ Helen to find out more about dental education, COPDEND and CPD standards.
}

\begin{abstract}
Why did you choose dentistry?
It wasn't the most logical decision I've ever made in my life. I didn't know what to study at university and hadn't really considered dentistry as an option. However, there was a book in the careers section of the school library that caught my attention. It was by the 'Stephen Hancocks of his day' - a chap called Matthew Finch - who wrote a humorous column on the back of one of the dental journals. He made dentistry sound like fun, and as, I'd always liked working with people, studying sciences and enjoyed doing practical things like needlework, I decided it might suit me. But I realise now that I went into it with my eyes firmly shut! It's been a really good career. Dentistry offers so many opportunities for people. I've had half a dozen careers, not just one!
\end{abstract}

\section{What attracted you to the world of dental education?} I've always taken pragmatic decisions about my career and life choices. About thirty years ago, I took a short career break from general practice soon after my daughter was born, and after that I was offered a job in a community dental service. It was through this that I found a farsighted mentor, Jane Rhodes. It was Jane who persuaded me to do a further education teaching certificate and on the back of that I got a job doing both clinical work and running dental health education teams. Jane felt very strongly, and she was ahead of her time, that it was not appropriate to go into schools to teach children if you didn't understand what you were doing. She felt

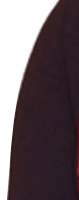

\section{'There is a} huge unmet need particularly with older and vulnerable people...'

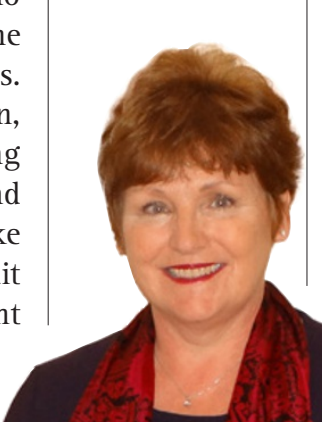


know from various research studies that the quality of CPD on offer is hugely variable; so how does any dental professional know they are getting a good deal? How do they know that a course that they are going to sign up for is the one that they need? People spend a lot of time and money on CPD, so they ought to have some proper assurances about what they are going to get.

The GDC have now published their new pilot scheme for enhanced CPD, which says that providers must have a quality assurance scheme. As an ordinary dentist how would you know if that is worth the paper it is written on?

The UK was well ahead of the game when starting to do verifiable CPD but when you look at what is happening in other countries now, it feels as if we've sat back since. For example, pharmacists in New Zealand band the quality of their CPD so the best quality CPD is that which results in improved care to patients. If you can demonstrate that you've done CPD that's improved patient care, that's worth three times as many CPD points as just sitting in a lecture half listening to the speaker and maybe reading a newspaper or catching up with emails in the back of the room. That sort of approach has also been adopted in parts of the USA, so they only count CPD where you can demonstrate that you have done something that has improved your patient care or outcomes. We have a long way to travel to get anywhere near that. I would just hope that we can start having conversations about what we are spending all this money on. Is it just to tick a box so we can stay registered or are we really trying to do it to improve ourselves and what we do for patients?

\section{The COPDEND guidelines have been criticised for being too academic. Are they practically useful?}

Locally, in my own deanery, we've drawn up an audit tool and through this looked at the COPDEND quality standards and investigated how they compare to what we do as a CPD provider. I agree it's a challenge - we haven't yet met all of what we classify as the 'essential

\section{'A lot of organisations charge a lot of money for courses and still don't meet the minimum CPD stand- ards or get anywhere near them...'}

standards'. But when I look at them I know that that it is what we should be doing and so we have made a plan and set ourselves some objectives. I think some people are put off because they look at the desirable standards straight away and feel bad that they aren't reaching that level. We have got to learn to walk properly before we can get there. The COPDEND standards are a stretch but they are reachable. I would hope that in time they will help to improve the quality of education and patient care. Many people and organisations charge a lot of money for CPD courses and still don't meet the minimum standards or get anywhere near them. That is not right.

\section{What are you most proud of?}

Professionally, I'm really proud of the work we have done on the educator standards that formalised the concept of focussing on education as well as dentistry. That was long overdue, so I'm pleased to have been able to influence that. The other thing that I'm really pleased about is the support we provided to help set up a specialty trainees' forum. Before this there had been no forum in dentistry for specialty trainees to meet together outside of their individual specialty silos. We supported them and helped them decide what they wanted to do. They then set up their own group and held a conference in November 2014. I'm really pleased and I hope that it goes from strength to strength. I really want to empower people to sort their own lives out and that's a great way of doing that.

Another thing I was involved with was establishing a national group for prison dentists. Again, they had never met together as a group and the nature of their work means they are really isolated. So we set up some conferences for them with a residential component. There were over 100 participants. We put on courses for them around the subjects that were relevant to them and their patients. We were able to help them to learn from each other and improve what they did. From this, the group set up the National Association of Prison Dentistry (UK) which now has a regular conference and useful website.
What do you see the dental team looking like in 10 years' time?

It's very interesting because I can remember the Nuffield Report (which is worth looking at again), which contained a lot of in-depth research looking at the dental team and how it might work. If you were in a completely managed system, then you would definitely say that you were going to be having many more DCPs and fewer dentists everywhere in the future. But because of the mixed economy nature of general practice and also because there are lots of small independent units, the optimum skill mix from a paper-based exercise looking solely at NHS provision, which might work in a big city practice, doesn't necessarily translate into a lone practice in a small market town, or somewhere rural or remote.

In the future, I see lots of different ways of delivering dentistry - I definitely think there will be more DCPs, and, if we can get the incentives right so that the dentists are actually doing the more complex work, that would be a good result. But there are so many perverse incentives in the system and so many complexities around a mixed economy and private/NHS and aesthetic dentistry. So much of it depends on the funding, contractual models and how much patients are being expected to contribute to the costs of their care. There are huge drivers in dentistry that we don't have in medicine. So I think in future it's going to be a segmented market with some places where we see a lot of DCPs delivering routine care and specialised private high-end care provided by dentists in other parts of the market. I do think general practice is here to stay, albeit with fewer, larger practices and more co-operation between small practices to allow them to survive economically.

If you had an extra $€ 12$ billion to spend on dentistry alone in the UK - what would you do?

I think you've got to start with the basics and ensure that there isn't a lesser standard being applied to anyone. There is a huge gap in terms of the support those new to UK dentistry receive. So if you're new to dentistry and UK-trained, you have foundation training and 
that's a good grounding. However, if you come in from overseas you don't get the same resource directed at you but you still have to learn the same sorts of things. I would like there to be the same level of support and compulsory training for all practitioners coming in to work in the UK, whether in the NHS or privately. I think it would be better for patients if the dentists fully understand the system they are working in and what the expectations are. That's really important.

From a public health perspective, there is a huge unmet need, particularly with older and vulnerable people. We need better training for dental professionals so that they can understand how to care for vulnerable people and older people with dementia. These are patients who can't seek out dental care very easily. We could use money to take the care to them and to put in place safety nets to ensure that they receive appropriate dental care. Whoever does it (be it community dentists, GDPs or DCPs), though it is not necessarily difficult dentistry, we must remember it is special care dentistry. Some of the patient issues are extremely difficult, time consuming and expensive. I don't think you can do it on the cheap. We need the right people with the right skills. However, we could make such a huge improvement to a person's quality of life if they have a comfortable mouth and they can eat well. Currently the incentives just aren't there.
If there were enough money for a comprehensive dental service free at the point of delivery, as with most of the rest of the NHS, that would be ideal.

\section{What do you like to do in your spare time?}

I haven't had a lot of spare time until recently, but I do like to spend what time I have with my friends and family. I like gardening. I've just begun growing vegetables and am enjoying pottering in the greenhouse. I love travelling and the sunshine - I've been to Bali three times and love it there. We have just been on a grand tour of northern India which was fascinating. I would like to do lots more travelling - there is so much more of the world to see and learn from. 